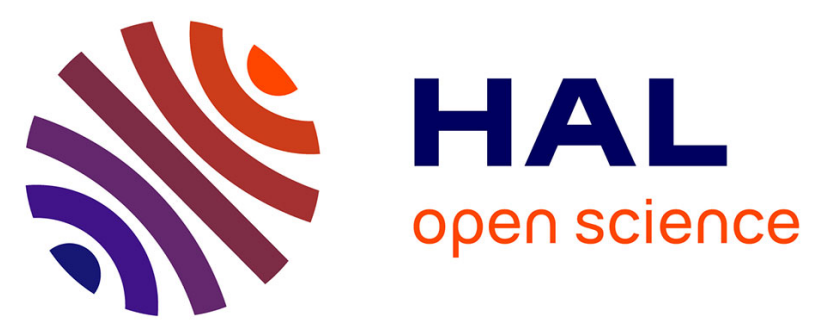

\title{
Optimization of an absolute sensitivity in a glassy matrix during DNP-enhanced multidimensional solid-state NMR experiments
}

Hiroki Takahashi, Carlos Fernandez-De-Alba, Daniel Lee, Vincent Maurel, Serge Gambarelli, Michel Bardet, Sabine Hediger, Anne-Laure Barra, Gaël de Paëpe

\section{To cite this version:}

Hiroki Takahashi, Carlos Fernandez-De-Alba, Daniel Lee, Vincent Maurel, Serge Gambarelli, et al.. Optimization of an absolute sensitivity in a glassy matrix during DNP-enhanced multidimensional solid-state NMR experiments. Journal of Magnetic Resonance, 2014, 239, pp.91-99. 10.1016/j.jmr.2013.12.005 . hal-02043248

\section{HAL Id: hal-02043248 https://hal.science/hal-02043248}

Submitted on 29 Sep 2021

HAL is a multi-disciplinary open access archive for the deposit and dissemination of scientific research documents, whether they are published or not. The documents may come from teaching and research institutions in France or abroad, or from public or private research centers.
L'archive ouverte pluridisciplinaire HAL, est destinée au dépôt et à la diffusion de documents scientifiques de niveau recherche, publiés ou non, émanant des établissements d'enseignement et de recherche français ou étrangers, des laboratoires publics ou privés. 
Optimization of an absolute sensitivity in a glassy matrix during DNP-enhanced multidimensional solid-state NMR experiments

Hiroki Takahashia , Carlos Fernandez de Alba ${ }^{a}$, Daniel Lee ${ }^{a}$, Vincent Maurela, Serge Gambarellia, Michel Bardeta ${ }^{a}$, Sabine Hedigera ${ }^{a}$ Anne-Laure Barra ${ }^{b}$, Gaël De Paëpe ${ }^{a, *}$

${ }^{a}$ Laboratoire de Chimie Inorganique et Biologique, UMR-E3 (CEA/UJF) and CNRS, Institut Nanosciences et Cryogénie, CEA, 38054 Grenoble, France

${ }^{\mathrm{b}}$ Laboratoire National des Champs Magnétiques Intenses, CNRS, F-38042 Grenoble, France

* Corresponding author.

E-mail: gael.depaepe@cea.fr

Phone: +33438786570 


\section{Abstract}

Thanks to instrumental and theoretical development, notably the access to high-power and high-frequency microwave sources, high-field dynamic nuclear polarization (DNP) on solid-state NMR currently appears as a promising solution to enhance nuclear magnetization in many different types of systems. In magicangle-spinning DNP experiments, systems of interest are usually dissolved or suspended in glass-forming matrices doped with polarizing agents and measured at low temperature (down to $\sim 100 \mathrm{~K}$ ). In this work, we discuss the influence of sample conditions (radical concentration, sample temperature, etc.) on DNP enhancements and various nuclear relaxation times which affect the absolute sensitivity of DNP spectra, especially in multidimensional experiments. Furthermore, DNP-enhanced solid-state NMR experiments performed at 9.4 $\mathrm{T}$ are complemented by high-field CW EPR measurements performed at the same magnetic field. Microwave absorption by the DNP glassy matrix is observed even below the glass transition temperature caused by softening of the glass. Shortening of electron relaxation times due to glass softening and its impact in terms of DNP sensitivity is discussed. 


\section{Introduction}

Dynamic nuclear polarization (DNP) is a hyperpolarization technique that transfers the larger polarization of electron spins to nuclear spins by microwave $(\mu \mathrm{w})$ irradiations near the electron spin resonances [1-5]. High-field DNP has been demonstrated to enhance sensitivity by one to two orders of magnitude for solid-state nuclear magnetic resonance (SSNMR) experiments. This high-field DNP work is indebted to the recent developments of high-power, high-frequency microwave sources (gyrotrons) [6-11], transmission lines [11-14], low-temperature magic-angle-spinning (MAS) probes $[13,15,16]$ and efficient polarizing agents [17-19] (TOTAPOL [20], bTbK [21], etc.) [22-26]. Griffin and co-workers demonstrated DNP experiments at 5 T [27-30] in the 1990's and the applicable magnetic fields have, since then, been extended to 9 [31], 14.1 [32] and recently 16.4 T [33]. DNP enhancement factors vary depending on various factors such as the sample temperature and the magnetic field. Typical DNP enhancement factors in ${ }^{1} \mathrm{H}-$ ${ }^{13} \mathrm{C}$ cross-polarization (CP) MAS experiments using the biradical TOTAPOL have been reported in the range of $20-80$ on small organic molecules $[25,34,35]$ and $20-30$ on membrane proteins [36-38] at $\sim 100$ $\mathrm{K}$ and $9.4 \mathrm{~T}$.

The DNP enhancement factor ( $\mathrm{DNP})$ mentioned above is measured by comparing the NMR spectra acquired with and without $\mu \mathrm{w}$ irradiation, usually in 1D experiments. However, for most of the applications of DNP, the only relevant factor to consider is a signal-to-noise ratio $(\mathrm{S} / \mathrm{N})$ per unit time available in multidimensional experiments. EDNP indeed contributes to enhancement of S/N in DNP experiments, but other factors such as signal bleaching, DNP build-up time, spectral linewidths, etc. also contribute positively/negatively to $\mathrm{S} / \mathrm{N}$ per unit time [39-41]. Thus, all of these factors need to be considered to evaluate effective DNP enhancement.

We have recently introduced a parameter dubbed the 'absolute sensitivity ratio (ASR)' to evaluate the effective DNP enhancement [40]. The ASR is experimentally obtained by comparing the S/N per unit time for a DNP experiment and a conventional SSNMR experiment. For conventional SSNMR, higher magnetic fields and different probes can easily be used to gain higher sensitivity. This fair comparison is extremely important to evaluate the actual usefulness of DNP and has already started to be used in the DNP 
community [42-44]. The ASR can be rationalized by eight different factors that contribute to the effective DNP enhancement as follows:

$$
\mathrm{ASR}=\varepsilon_{\mathrm{DNP}} \cdot \varepsilon_{\mathrm{T}} \cdot \eta_{\mathrm{T} 1} \cdot \chi_{\mathrm{bleach}} \cdot \chi_{\mathrm{LW}} \cdot \chi_{\mathrm{weight}} \cdot \chi_{\mathrm{seq}} \cdot \chi_{\mathrm{ex}}
$$

where $\varepsilon_{\mathrm{T}}$ is the gain due to performing the measurement at a low temperature (increase of magnetization due to the Boltzmann distribution and the reduction of thermal noise), $\eta_{\mathrm{T} 1}$ takes into account the different repetition times for DNP and conventional NMR experiments, $\chi$ bleach is the factor accounting for signal bleaching, $\chi_{\mathrm{LW}}$ is the ratio of the linewidths, $\chi_{\text {weight }}$ is the ratio of the effective sample weights, $\chi_{\text {seq }}$ is the ratio of the effective magnetization after decays during the pulse sequence, and $\chi_{\mathrm{ex}}$ is the factor allowing extra effects (e.g. when using a different probe, magnetic field, etc.).

In MAS-DNP experiments, samples of interest are usually dissolved [29,30,45-47] or suspended [36-38,48-57] in glass-forming matrices (containing water and a cryo-protectant such as glycerol or DMSO) doped with polarizing agents and measured at low temperature (typically down to $\sim 100 \mathrm{~K}$ ). All the above factors are strongly dependent on the sample conditions (sample temperature, solvents and cryo-protectants, radical concentration, etc.). Therefore, the sample condition carefully needs to be adjusted to optimize these factors. It is important to note that $\chi_{\text {seq }}$ can be a major factor for the reduction of an ASR when performing multidimensional experiments that contain refocused evolution (refocused INADEQUATE [58], SARCOSY [59], etc.) and/or spin-locking periods, since decay parameters such as refocusable transverse decay times $\left(T_{2}^{\prime}\right)[58,60]$ and spin-locking decay times $\left(T_{1} \rho\right)$ are strongly affected by the sample condition $[35,61,62]$.

In this paper, we discuss various effects on the above parameters in order to optimize an ASR for DNP-enhanced multidimensional SSNMR experiments performed using a glassy-matrix. We will demonstrate that apparent linewidths, usually broader at low temperatures, can conceal a global shortening of other nuclear decay times, which can have deleterious effects on multidimensional experiments. Application of these studies is demonstrated on natural-abundance cellulose using 2D refocused INADEQUATE. Moreover, we complement our 9.4 T DNP experiments by performing high-field EPR 
experiments at this magnetic field. Notably, it is shown that the rigidity of the frozen glassy matrices needs to be taken into account since microwave absorption is observed even below the glass transition temperature. Softening of glass also results in a shortening of longitudinal relaxation times of electron spins $\left(T_{1 \mathrm{e}}\right)$ especially at high magnetic fields, which leads to a reduction of DNP efficiency.

\section{Materials and methods}

\subsection{Sample preparation}

The biradical TOTAPOL was synthesized according to the literature $[20] .{ }^{13} \mathrm{C}$-2-glycine, ${ }^{13} \mathrm{C}$-urea, and natural abundance cellulose were purchased from Sigma-Aldrich (Lyon, France). Glycine and urea samples were dissolved in $\mathrm{d}_{6}-\mathrm{DMSO} / \mathrm{D}_{2} \mathrm{O} / \mathrm{H}_{2} \mathrm{O}(6: 3: 1$ in volume ratio) solutions containing TOTAPOL at various concentrations specified in the text below or in the figure captions. The above solutions $(40 \mu \mathrm{L})$ were fully packed into $3.2-\mathrm{mm}$ thin-wall zirconia rotors. $50 \mathrm{mg}$ of the cellulose was suspended in the above DNP matrix along with $10 \mathrm{mM}$ of TOTAPOL and centrifuged into a 3.2-mm thin-wall zirconia rotor. The desired room-temperature sample was then inserted and cooled to approximately $105 \mathrm{~K}$ directly in the precooled DNP probehead. When needed, the sample temperature was then increased in the probehead to the desired value.

\subsection{DNP experiments}

All experiments were performed on a Bruker AVANCETM III $400 \mathrm{MHz}$ wide-bore NMR system equipped with a $263 \mathrm{GHz}$ gyrotron, a transmission line and a low temperature $(\sim 100 \mathrm{~K})$ capable triple resonance 3.2-mm MAS probe [25]. All data were recorded, processed and analyzed using Bruker Topspin 3.0. The sample temperature and MAS frequency were $105 \mathrm{~K}$ and $8 \mathrm{kHz}$, respectively, unless otherwise specified. The pulse sequences are shown in Fig. 1 and were used for $T_{2}{ }^{\prime}\left({ }^{13} \mathrm{C}\right)$ measurements $(\mathrm{a}), T_{1 \rho}\left({ }^{1} \mathrm{H}\right)$ measurements (b) and 2D refocused INADEQUATE experiments (c). 263-GHz microwaves ( $\sim 5 \mathrm{~W})$ were continuously irradiated throughout the DNP experiments. For all experiments, the ${ }^{1} \mathrm{H}$ RF amplitudes were $100 \mathrm{kHz}$ for the $\pi / 2$ pulses and the SPINAL-64 decoupling [63] during the evolution and detection periods 
unless otherwise stated. The ${ }^{13} \mathrm{C} \mathrm{CP}$ pulse was applied at a RF field strength of $60 \mathrm{kHz}$ and the ${ }^{1} \mathrm{H}$ RF field strength was adjusted to $80 \mathrm{kHz}$ (at maximum) to match a Hartmann-Hahn condition using a linear ramp with a contact time of $1-2 \mathrm{~ms}$. The ${ }^{13} \mathrm{C}$ hard pulses were set to $80 \mathrm{kHz}$. Other NMR parameters are specified in the text below.

Precise measurement of the sample temperature relied on the protocol proposed by Thurber and Tycko, where the real sample temperature is shown to be phenomenologically related to the ${ }^{79} \mathrm{Br} T_{1}$ relaxation time constant in $\mathrm{KBr}$ [64]. A small quantity (5 mg) of $\mathrm{KBr}$ wrapped in Teflon was inserted at the bottom of the rotor, on the top of which the sample of interest was loaded as usual. The $T_{1}$ relaxation time constant of ${ }^{79} \mathrm{Br}$ resonance was obtained by a standard saturation-recovery experiment.

\subsection{High-field EPR experiments}

CW High-field EPR spectra were recorded on a double-pass transmission EPR spectrometer operating in Faraday configuration at temperatures in the range of $100 \mathrm{~K}$ to $180 \mathrm{~K}$. The DNP sample was placed in a Teflon cup and inserted at liquid $\mathrm{N}_{2}$ temperature in the variable temperature insert of the superconducting magnet. The Teflon cup is filled over a height of a few millimeters (typically $\sim 8 \mathrm{~mm}$ ), which corresponds to several wavelengths of the exciting radiation. The $285-\mathrm{GHz}$ microwaves $(\lambda \sim 1.05$ $\mathrm{mm}$ ) were generated by a $95 \mathrm{GHz}$ Gunn diode equipped with a tripler and were transmitted via a quasioptical set-up [65]. The detection of microwave absorption was performed with a hot electron $\mathrm{InSb}$ bolometer. The temperature was measured with the help of a Cernox sensor placed outside the modulation coil at the height of the sample. In this way, the thermometer is able to indicate the heating effect due to the modulation when it exists. It is to note that all high-field EPR experiments were performed in a regime below saturation of the signal. 


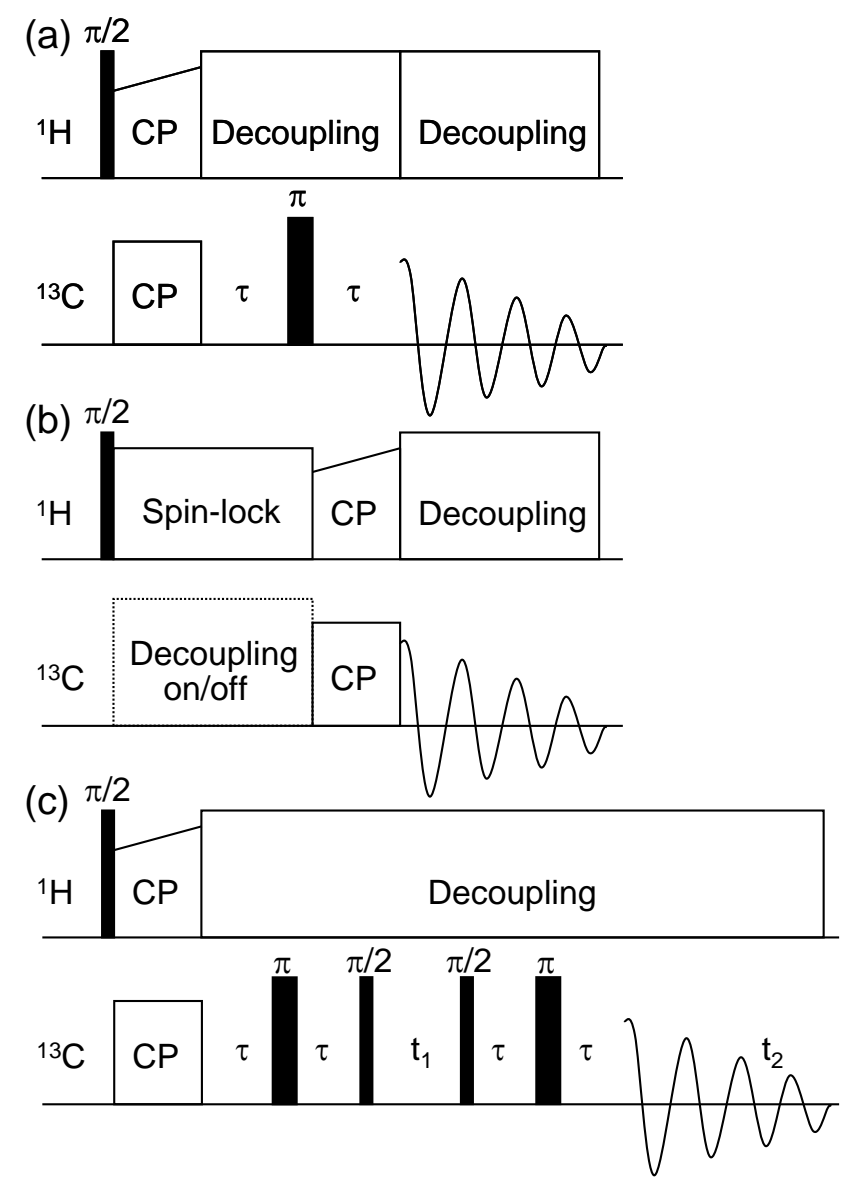

Figure 1. Pulse sequences for $T_{2}{ }^{\prime}\left({ }^{13} \mathrm{C}\right)$ measurements (a), $T_{1 \rho}\left({ }^{1} \mathrm{H}\right)$ measurements (b) and $2 \mathrm{D}$ refocused INADEQUATE experiments (c). 263-GHz microwaves ( $\sim 5 \mathrm{~W})$ were continuously irradiated throughout the entire duration of the DNP experiments.

\section{Results and discussion}

The eight parameters that compose the ASR in Eq. (1) are affected by many factors (see Table 1) including electron and nuclear relaxation times, microwave $B_{1}$ irradiation amplitude, sample temperature, radical concentration, etc. Herein, we assume for simplicity that the magnetic field, the type of probe, etc. are the same and that the sample of interest is dissolved in a given DNP matrix. Most of parameters contributing to ASR (given in Table 1) are affected by radical concentration and sample temperature directly and/or indirectly. In this work, therefore, we will focus on the influence of these two experimental parameters on the measured ASR. 
Table 1. Parameters directly affecting the various ASR contributions.

\section{Relevant parameters}

\begin{tabular}{ll}
\hline$\varepsilon_{\mathrm{DNP}}$ & Electron and nuclear relaxation times, $\mu \mathrm{w} B_{1 \mathrm{e}}$, \\
& polarizing agents, etc. \\
\hline$\varepsilon_{\mathrm{T}}$ & Boltzmann factor, thermal noise \\
\hline$\eta_{\mathrm{T} 1}$ & Nuclear relaxation times $\left(T_{\mathrm{ln}}\right)$ \\
\hline$\chi_{\text {bleach }}$ & Radical concentration, etc. \\
\hline$\chi_{\mathrm{LW}}$ & Apparent linewidths $\left(1 / \pi T_{2}{ }^{*}\right)$ \\
\hline$\chi_{\text {weight }}{ }^{\mathrm{a}}$ & Solubility \\
\hline$\chi_{\text {seq }}$ & Relaxation parameters $\left(T_{2}{ }^{2}, T_{1} \rho\right.$, etc. $)$ \\
\hline$\chi_{\mathrm{ex}}$ & N. A. \\
\hline a This becomes larger when using a suspension method
\end{tabular}

a This becomes larger when using a suspension method.

3.1. Measurement of refocused transverse decay times in frozen solutions

The apparent transverse decay time, $T_{2}{ }^{*}$, determines $\chi_{\mathrm{LW}}$ (see Table 1). Apparent spectral linewidths $\left(1 / \pi T_{2}^{*}\right)$ for frozen solutions are typically much broader than for powdered solids. For instance, the ${ }^{13} \mathrm{C}$ linewidth of the $\alpha$-carbon peak of glycine in a frozen DMSO/water solution is $240 \mathrm{~Hz}$ in the absence of paramagnetic doping at $\sim 100 \mathrm{~K}$ and $9.4 \mathrm{~T}$ (compare this to a linewidth of $49 \mathrm{~Hz}$ measured at $9.4 \mathrm{~T}$ and room temperature on powdered glycine). This broadening of the lines in frozen solutions corresponds to conformational distribution frozen at a low temperature [66]. This is one of the major limitations of the DNP approach, especially for biomolecular systems, which thus needs to be tackled by, for example, sparse isotopic labeling strategies. However, this inhomogeneous broadening has another potential risk as it can hide the influence of paramagnetic doping on the transverse relaxation times of nuclear spins. In such a situation, radical concentrations cannot be optimized by analysis of the apparent linewidths of the samples of interest. 
The transverse NMR signal decay resulting from conformational distribution, which leads to an inhomogeneous line-broadening, can be 'refocused' by introducing an echo period into the pulse sequence as illustrated in Fig. 1(a) for the 1D ${ }^{13} \mathrm{C}$-CPMAS pulse sequence [58]. This sequence can be used to indirectly measure $T_{2}^{\prime} \cdot T_{2}$ ' is not affected by inhomogeneous (refocusable) interactions such as the chemical shift distribution but is affected by heteronuclear dipolar couplings (and thus the [in]efficiency of ${ }^{1} \mathrm{H}$ decoupling) and paramagnetic doping. Consequently, $T_{2}{ }^{\prime}$ is typically much longer than $T_{2}{ }^{*}$. In order to truly observe the influence of paramagnetic doping, the efficiency of ${ }^{1} \mathrm{H}$ decoupling first needs to be analyzed.

Figure 2 shows the dependence of the peak height on the ${ }^{1} \mathrm{H}$ decoupling during the echo period using the pulse sequence in Fig. 1(a) on $2 \mathrm{M}{ }^{13} \mathrm{C}$-urea and $0.1 \mathrm{M}{ }^{13} \mathrm{C}$-2-glycine with $20 \mathrm{mM}$ TOTAPOL in $\mathrm{d}_{6}-\mathrm{DMSO} / \mathrm{D}_{2} \mathrm{O} / \mathrm{H}_{2} \mathrm{O}(6: 3: 1$ by volume). Constant durations for the echo periods of 9.0 and 5.4 ms were chosen for urea and glycine, respectively. Two types of ${ }^{1} \mathrm{H}$ decoupling, $\mathrm{CW}$ decoupling (open symbols) and SPINAL-64 (filled symbols), were used during the echo period. As expected, SPINAL-64 is a more efficient decoupling technique. For the carbonyl group of urea (circles), where there are no ${ }^{1} \mathrm{H}$ spins directly bonded, relatively low power decoupling $(90 \mathrm{kHz})$ is required to effectively suppress ${ }^{13} \mathrm{C}-{ }^{1} \mathrm{H}$ dipolar couplings, whereas over $120 \mathrm{kHz}$ of decoupling strength is needed for the $\mathrm{C}^{\alpha}$ group of glycine (triangles) where two ${ }^{1} \mathrm{H}$ spins are covalently bonded. Therefore, with sufficient ${ }^{1} \mathrm{H}$ decoupling, the peak height reaches a plateau where the $T_{2}$ ' of ${ }^{13} \mathrm{C}$ is mainly affected by paramagnetic doping. Herein, we use 100 (for urea) and $120 \mathrm{kHz}$ (for glycine) of SPINAL-64 ${ }^{1} \mathrm{H}$ decoupling during the echo period for $T_{2}$ ' measurements, used to discuss the effects of radical concentration and sample temperature. 


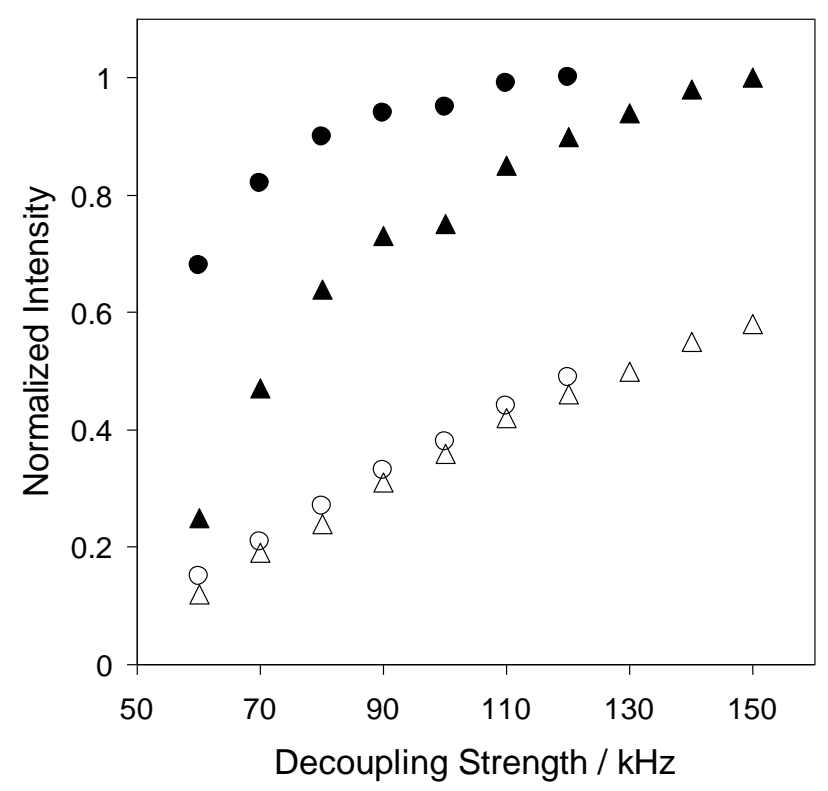

Figure 2. Influence of ${ }^{1} \mathrm{H}$ decoupling strength during an echo period (Fig. 1a). The samples are $2 \mathrm{M}{ }^{13} \mathrm{C}$ urea (circles) and $0.1 \mathrm{M}^{13} \mathrm{C}$-2-glycine (triangles) with $20 \mathrm{mM}$ TOTAPOL in $\mathrm{d}_{6}-\mathrm{DMSO} / \mathrm{D}_{2} \mathrm{O} / \mathrm{H}_{2} \mathrm{O}(6: 3: 1$ by volume) in a 3.2-mm thin-wall zirconia rotor. Open and filled symbols represent CW and SPINAL-64 decoupling, respectively.

\subsection{Optimization of radical concentration for multidimensional DNP experiments}

Figure 3(a) shows the variation of $T_{2}$ ' for the urea sample at various TOTAPOL concentrations as a function of the echo time using the pulse sequence in Fig. 1(a). Drastic reduction of $T_{2}$ ' is seen even at a low concentration of $10 \mathrm{mM}\left(T_{2}{ }^{\prime}=13 \mathrm{~ms}\right.$, cf. $T_{2}{ }^{\prime}=46 \mathrm{~ms}$ at $0 \mathrm{mM}$ TOTAPOL $)$. In the absence of relaxation, the optimal echo period in the refocused INADEQUATE, shown in Fig. 1(c), should be approximately 15$30 \mathrm{~ms}$ based on a J-coupling of $30-60 \mathrm{~Hz}$. At $0 \mathrm{mM}$ TOTAPOL concentration, $T_{2}$ ' is about $46 \mathrm{~ms}$, which translates into a polarization transfer efficiency of $72 \%$ at $15 \mathrm{~ms}$ echo time and $52 \%$ at $30 \mathrm{~ms}$. The addition of polarizing agents leads to a reduction of the refocused transverse dephasing time. For instance at $10 \mathrm{mM}$ TOTAPOL concentration, $T_{2}$ ' is about $10 \mathrm{~ms}$ which translates into 32 and $10 \%$ of polarization transfer efficiencies at 15 and $30 \mathrm{~ms}$, respectively. For $60 \mathrm{mM}$ TOTAPOL concentration, magnetization decays very rapidly, which prohibits efficient implementation of 2D experiments utilizing refocused evolutions. Note that in Figure 3(a) dephasing curves can be fitted by mono-exponential curves, which suggests that the 
detectable nuclear spins are uniformly affected by paramagnetic doping.

The dependence upon TOTAPOL concentration of $T_{1}\left({ }^{1} \mathrm{H}\right), T_{1 \rho}\left({ }^{1} \mathrm{H}\right), T_{2} \cdot\left({ }^{13} \mathrm{C}\right)$ and $T_{2} *\left({ }^{13} \mathrm{C}\right)$ on the urea sample is shown in Fig. 3(b). The pulse sequence in Fig. 1(b), with a ${ }^{1} \mathrm{H}$ spin-locking field of $80 \mathrm{kHz}$ and no ${ }^{13} \mathrm{C}$ decoupling, was used to measure the $T_{1 \rho}$ of the ${ }^{1} \mathrm{H}$ spins. All parameters except for $T_{2} *$ drop dramatically as the concentration of TOTAPOL increases. This suggests that $T_{1}, T_{1}$ and $T_{2}$ ' are dominated by paramagnetic effects, even at low radical concentrations for which the DNP enhancement factor is suboptimal. On the contrary, $T_{2}{ }^{*}$ appears insensitive to radical concentration up to high biradical concentration ( $60 \mathrm{mM}$ in this case). The broadening of the lines is mainly inhomogeneous (i.e. it can be refocused by a Hahn-echo) for low radical concentration and arises from a chemical shift distribution of the molecules trapped in the frozen solution. It is worth noting that the observed linewidths do not change until $T_{2}$ ' becomes equal to $T_{2}^{*}$ (at $60 \mathrm{mM}$ in this case). Apparent linewidths are thus not a relevant parameter in the optimization of radical concentration, especially when performing multidimensional NMR experiments.

For multidimensional NMR experiments, $\chi_{\text {seq }}$ in Eq. (1) can be a major factor in the reduction of an ASR, particularly when the pulse sequence contains refocused evolution and/or spin-locking periods during which specific time constants have to be considered. In this case, we need to consider the cumulative effect of the DNP enhancement and the decays as a function of radical concentration. In order to evaluate such effects, it is convenient to use the reduced form of the ASR (ASR ${ }^{r}$, described in our previous paper [40]. This $\mathrm{ASR}^{\mathrm{r}}$ keeps certain factors constant and thus permits the detailed analysis of the effects of the other parameters.

To observe the radical concentration dependence for a glassy DNP matrix (by comparing samples with and without polarizing agents at the same temperature), a $\mathrm{ASR}^{\mathrm{r}}$ can be written as:

$$
\mathrm{ASR}_{\mathrm{T}, \text { weight,ex }}^{\mathrm{r}}=\frac{\mathrm{ASR}}{\varepsilon_{\mathrm{T}} \cdot \chi_{\mathrm{LW}}^{\mathrm{T}} \cdot \chi_{\text {weight }} \cdot \chi_{\mathrm{ex}}}=\varepsilon_{\mathrm{DNP}} \cdot \eta_{\mathrm{T} 1} \cdot \chi_{\text {bleach }} \cdot \chi_{\mathrm{LW}}^{\text {radical }} \cdot \chi_{\mathrm{seq}}
$$

where $\chi_{\mathrm{LW}}^{\mathrm{T}}$ and $\chi_{\mathrm{LW}}^{\text {radical }}$ are the parameters accounting for line-broadening caused by low temperature and 
radical doping, respectively. As seen above, $\chi_{\mathrm{LW}}^{\text {radical }}$ is negligible for frozen solution samples at a low concentration of polarizing agents (below $60 \mathrm{mM}$ in this case). In a refocused INADEQUATE experiment, the signal-decay factor during the pulse sequence $\left(\chi_{\text {seq }}\right)$ is mainly composed of factors caused by $T_{1 \rho}$ and $T_{2}$ ' decays $\left(\chi_{\text {seq }}=\chi_{\mathrm{T} 1 \rho} \cdot \chi_{\mathrm{T} 2^{\prime}}\right)$. Thus, Eq. $(2)$ can be rewritten as

$$
\mathrm{ASR}_{\mathrm{T}, \text { weight,ex }}^{\mathrm{r}}=\varepsilon_{\mathrm{DNP}} \cdot \eta_{\mathrm{T} 1} \cdot \chi_{\text {bleach }} \cdot \chi_{\mathrm{T} 1 \rho} \cdot \chi_{\mathrm{T}^{\prime}} \cdot
$$

Figure 3(c) shows the cumulative effect of the factors in Eq. (3) which were obtained experimentally. Squares represent $\varepsilon_{\mathrm{DNP}}$ and the effect of $\eta_{\mathrm{T} 1}$ is added to it and indicated by crosses. Likewise, $\chi_{\text {bleach, }} \chi_{\mathrm{T} 1 \rho}$ and $\chi_{\mathrm{T} 2}$, are included cumulatively and their added effects are represented by triangles, filled circles and open circles, respectively. EDNP is maximal at $20 \mathrm{mM}$ and slowly decreases with increase of TOTAPOL concentration, while $\varepsilon_{\mathrm{DNP}} \cdot \eta_{\mathrm{T} 1}$ increases with the TOTAPOL concentration and reaches a maximum of 148 at $60 \mathrm{mM}$. Signal bleaching is an important factor to be considered for DNP experiments [35] and the optimum concentration becomes $10 \mathrm{mM}$ when it is included. Finally, $T_{1 \rho}$ decay and especially $T_{2}$ ' decay in this case reduces signal intensities. The effective DNP enhancement after the inclusion of both these parameters ( $\mathrm{ASR}_{\mathrm{T} \text {, weight,ex }}^{\mathrm{r}}$ ), when compared to the sample without TOTAPOL at the same temperature, is represented by open circles and optimal at $10 \mathrm{mM}$ TOTAPOL concentration. 

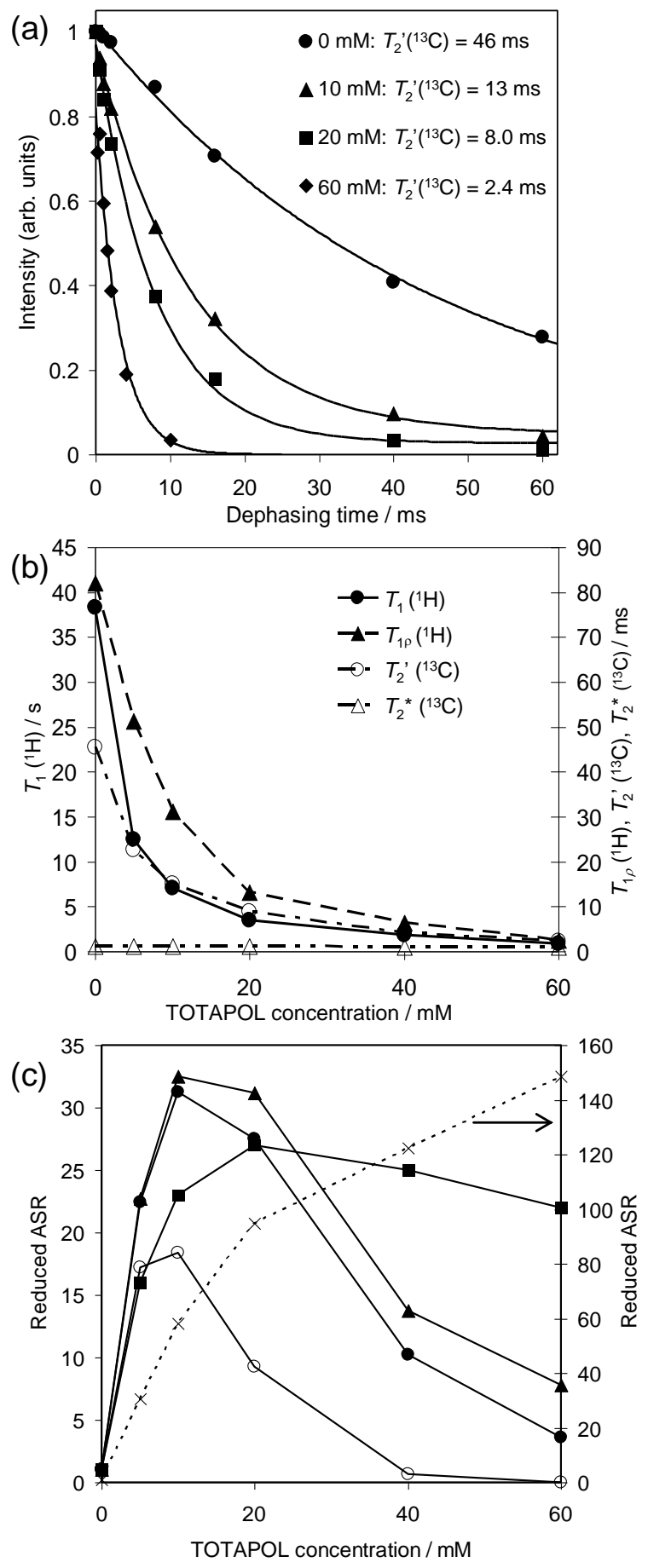

Figure 3. (a,b) Concentration dependence of relaxation parameters on $2 \mathrm{M}{ }^{13} \mathrm{C}$-urea in $\mathrm{d}_{6}-\mathrm{DMSO} / \mathrm{D}_{2} \mathrm{O} / \mathrm{H}_{2} \mathrm{O}$ (6:3:1 by volume) with various TOTAPOL concentrations at a sample temperature of $105 \mathrm{~K}$. (c) The cumulative effects of the factors from (b) as found, for example, in a refocused INADEQUATE experiment. Squares, crosses, triangles, filled circles and open circles represent $\varepsilon_{\mathrm{DNP}}, \varepsilon_{\mathrm{DNP}} \cdot \eta_{\mathrm{T} 1}, \varepsilon_{\mathrm{DNP}} \cdot \eta_{\mathrm{T} 1} \cdot \chi_{\mathrm{bleach}}$, $\varepsilon_{\mathrm{DNP}} \cdot \eta_{\mathrm{T} 1} \cdot \chi_{\text {bleach }} \cdot \chi_{\mathrm{T} 1 \rho}, \varepsilon_{\mathrm{DNP}} \cdot \eta_{\mathrm{T} 1} \cdot \chi_{\text {bleach }} \cdot \chi_{\mathrm{T} 1} \rho^{\cdot} \chi_{\mathrm{T} 2}$, respectively. The right $\mathrm{y}$-axis in (c) is used for the data represented by crosses. Lines are used as guides only. 
Taking into account the discussions above, a 2D refocused INADEQUATE experiment was demonstrated on natural-abundance semi-crystalline cellulose in a glass-forming solution (the same DNP solution as above experiments). Semi-crystalline cellulose was suspended in the DNP matrix at $10 \mathrm{mM}$ TOTAPOL. $T_{2}$ ' was $26 \mathrm{~ms}$ that is long enough to perform NMR experiments that employ refocused evolutions (the total echo period used for the $2 \mathrm{D}$ experiment was $16 \mathrm{~ms}$ ). The spectrum in Fig. 4 was obtained in 7 hours and all one-bond correlations of cellulose are seen and indicated by solid lines. Though signals from amorphous regions are broad and less intense, some of correlations of amorphous cellulose are also observed in the same spectrum indicated by dotted lines.

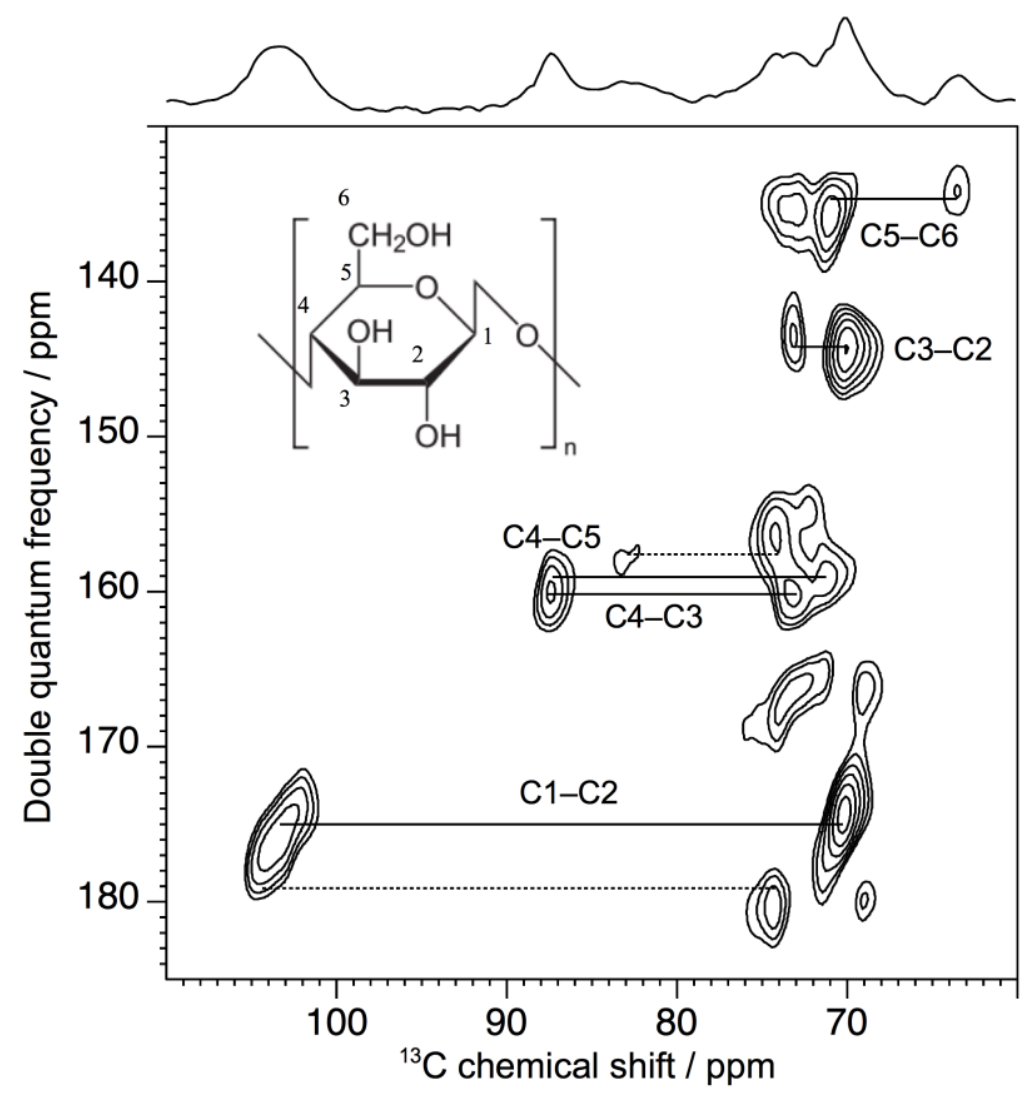

Figure 4. A DNP-enhanced ${ }^{13} \mathrm{C}-{ }^{13} \mathrm{C}$ 2D refocused INADEQUATE spectrum of natural-abundance semicrystalline cellulose in $\mathrm{d}_{6}-\mathrm{DMSO} / \mathrm{D}_{2} \mathrm{O} / \mathrm{H}_{2} \mathrm{O}(6: 3: 1$ by volume) containing $10 \mathrm{mM}$ TOTAPOL recorded at $105 \mathrm{~K}$. The spectrum was obtained in 7 hours with a recycle delay of $8 \mathrm{~s}$ and $16 \mathrm{~ms}$ (in total, $4 \tau$ ) of echo periods at a MAS frequency of $8 \mathrm{kHz}$. 64 scans were accumulated for each $t_{1}$ point (the number of complex $t_{1}$ points is 24 and the total $t_{1}$ evolution time is $1.5 \mathrm{~ms}$ ). The experimental data were apodized with 100 and 
$200 \mathrm{~Hz}$ of exponential line-broadening in $t_{2}$ and $t_{1}$ dimensions, respectively. The projection is shown on top.

\subsection{Effects of sample temperature in glassy solutions}

Temperature also changes sample conditions and influences $\varepsilon_{\mathrm{DNP}}, \varepsilon_{\mathrm{T}}, \eta_{\mathrm{T} 1}$ and $\chi_{\text {seq }}$ in Eq. (1). $\chi_{\text {bleach }}$ could potentially be affected by sample temperature but there was no clear influence of the temperature for the experiments reported here. Figure 5 (a) reports the effect of the sample temperature on the same set of parameters as the radical concentration dependence above (i.e. DNP enhancement factor and nuclear time decays $\left.T_{1}, T_{1}, T_{2}, T_{2}^{*}\right)$. All parameters except for $T_{2}^{*}$ appear sensitive to temperature variation and decay when the sample temperature increases from 100 to $160 \mathrm{~K}$. The change in slope of the $T_{1}$ and $T_{2}$ ' curves around $140 \mathrm{~K}$ most probably reflects the approach of the glass transition temperature, in agreement with literature [67].

This tendency is similar to that seen on the radical concentration where all the parameters are dominated by paramagnetic effects. For the temperature dependence, however, glass condition additionally needs to be considered since glass becomes softer as the temperature increases even below the glass transition temperature (around $140 \mathrm{~K}$ in our case). Softening of glass causes shortening of nuclear and electron relaxation times by molecular motion as well as microwave absorption by the glassy solution. Both phenomena will result in severe reduction of DNP efficiency and are specifically discussed in the section 3.4 .

Similarly to the section 3.2, $\mathrm{ASR}^{\mathrm{r}}$ for sample-temperature dependence in a glassy DNP matrix (by comparing to the without-TOTAPOL sample at $105 \mathrm{~K}$ ) can be expressed as

$$
\operatorname{ASR}_{\mathrm{T}(105 \mathrm{~K}), \text { weight,ex }}^{\mathrm{r}}=\frac{\mathrm{ASR}}{\varepsilon_{\mathrm{T}(105 \mathrm{~K})} \cdot \chi_{\text {weight }} \cdot \chi_{\mathrm{ex}}}=\varepsilon_{\mathrm{DNP}} \cdot \frac{\varepsilon_{\mathrm{T}}}{\varepsilon_{\mathrm{T}(105 \mathrm{~K})}} \cdot \eta_{\mathrm{T} 1} \cdot \chi_{\text {bleach }} \cdot \chi_{\text {seq }} .
$$

Here again, $\chi_{\mathrm{LW}}$ is neglected since $T_{2}{ }^{*}$ does not change in this temperature range in a frozen solution as seen in Fig. 5(a). $\varepsilon_{\mathrm{T}(105 \mathrm{~K})}$ is the gain from Boltzmann distribution at $105 \mathrm{~K}$ (reduction of thermal noise is neglected herein for convenience.). Figure 5(b) shows the cumulative effect of the factors in Eq. (4) in the same sense as above for the concentration dependence. The effective DNP enhancement (compared to the 
without-TOTAPOL sample at $105 \mathrm{~K}$ ) is represented by open circles. The same symbols are used as Fig. $3(\mathrm{c})$ and open squares are added to represent $\varepsilon_{\mathrm{DNP}} \cdot\left(\varepsilon_{\mathrm{T}} / \varepsilon_{\mathrm{T}(105 \mathrm{~K})}\right)$.

It is very important to stress again that ENN does not represent a "real gain" of a DNP experiment especially when performing multidimensional experiments. Sample conditions such as radical concentration, sample temperature and DNP matrices need to be optimized by measuring an ASR.

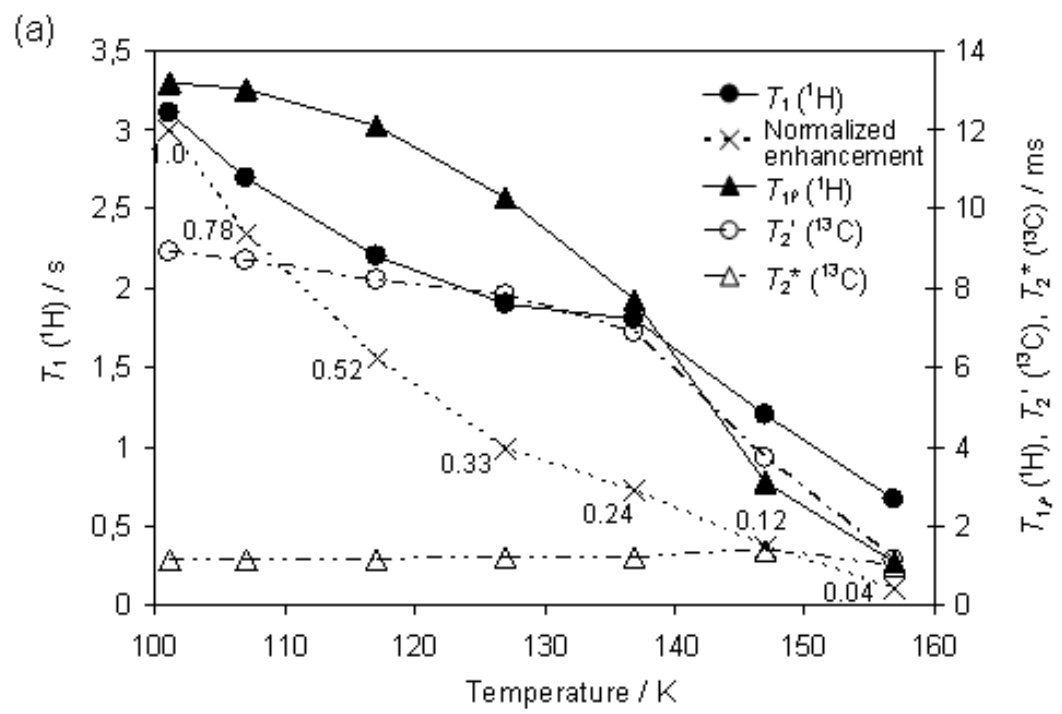

(b)

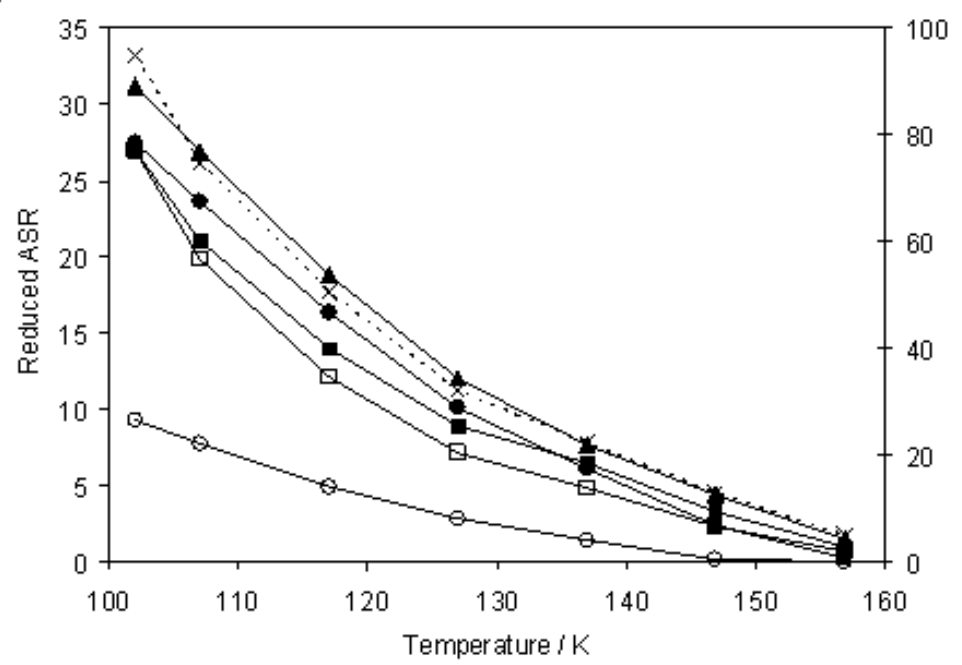

Figure 5. (a) Temperature dependence of relaxation parameters on $2 \mathrm{M}{ }^{13} \mathrm{C}$-urea in $\mathrm{d}_{6}-\mathrm{DMSO} / \mathrm{D}_{2} \mathrm{O} / \mathrm{H}_{2} \mathrm{O}$ (6:3:1 by volume) doped with $20 \mathrm{mM}$ TOTAPOL. (b) The cumulative effects of (a). Filled squares, open squares, crosses, triangles, filled circles and open circles represent $\varepsilon_{\mathrm{DNP}}, \quad \varepsilon_{\mathrm{DNP}} \cdot\left(\varepsilon_{\mathrm{T}} / \varepsilon_{\mathrm{T}(105 \mathrm{~K})}\right)$, $\varepsilon_{\mathrm{DNP}} \cdot\left(\varepsilon_{\mathrm{T}} / \varepsilon_{\mathrm{T}(105 \mathrm{~K})}\right) \cdot \eta_{\mathrm{T} 1}, \quad \quad \varepsilon_{\mathrm{DNP}} \cdot\left(\varepsilon_{\mathrm{T}} / \varepsilon_{\mathrm{T}(105 \mathrm{~K})}\right) \cdot \eta_{\mathrm{T} 1} \cdot \chi_{\text {bleach }}, \quad \quad \varepsilon_{\mathrm{DNP}} \cdot\left(\varepsilon_{\mathrm{T}} / \varepsilon_{\mathrm{T}(105 \mathrm{~K})}\right) \cdot \eta_{\mathrm{T} 1} \cdot \chi_{\text {bleach }} \cdot \chi_{\mathrm{T} 1 \rho}$, $\varepsilon_{\mathrm{DNP}} \cdot\left(\varepsilon_{\mathrm{T}} / \varepsilon_{\mathrm{T}(105 \mathrm{~K})}\right) \cdot \eta_{\mathrm{T} 1} \cdot \chi_{\text {bleach }} \chi_{\mathrm{T} 1 \rho} \cdot \chi_{\mathrm{T} 2}$, respectively $(\mathrm{b})$. The y-axes on the right are used for crosses $(\mathrm{b})$. 
Lines are used as guides only.

\subsection{Impact of glass softening probed by EPR}

In this study, we have used the biradical TOTAPOL that provides inhomogeneous broadening of the EPR spectrum, which then facilitates one of the DNP mechanisms of cross effect (CE) [23,24,68-71]. The field sweep profile of a DNP experiment reaches a maximum when the number of pairs of radicals which more or less experience the CE matching condition is maximized (Fig. 6a). EDNP (the maximum intensity of the filed sweep profile) based on this mechanism follows $B_{0}^{-1}$, since the number of electron-spin pairs experiencing the $\mathrm{CE}$ matching condition decreases as $B_{0}$ increases, which results from inhomogeneous broadening caused by g-anisotropy (Fig. 6b). This field dependence $\left(B_{0}{ }^{-1}\right)$ of DNP enhancements was theoretically and experimentally demonstrated at 5 and $9 \mathrm{~T}[19,71]$.

A recent theoretical study by Thurber et al. shows that in addition to the $B_{0}{ }^{-1}$ dependence above, a polarization transfer time constant (from electron spins to nuclear spins) is dependent on the magnetic field as $B_{0}{ }^{3}$ [72]. This is based on the level crossing model for MAS-DNP experiments [72,73]. A longer time constant at a higher magnetic field will lead to smaller DNP enhancement provided that the other parameters $\left(T_{1 \mathrm{e}}, T_{1 \mathrm{n}}\right.$, etc.) are the same. However, such parameters also depend on the magnetic field and on the sample condition (radical concentration, sample temperature, etc.) and are thus complicated to predict by theory. In the following, we will discuss other contributions that strongly affect the DNP efficiency but are not explicitly included in the theory. 


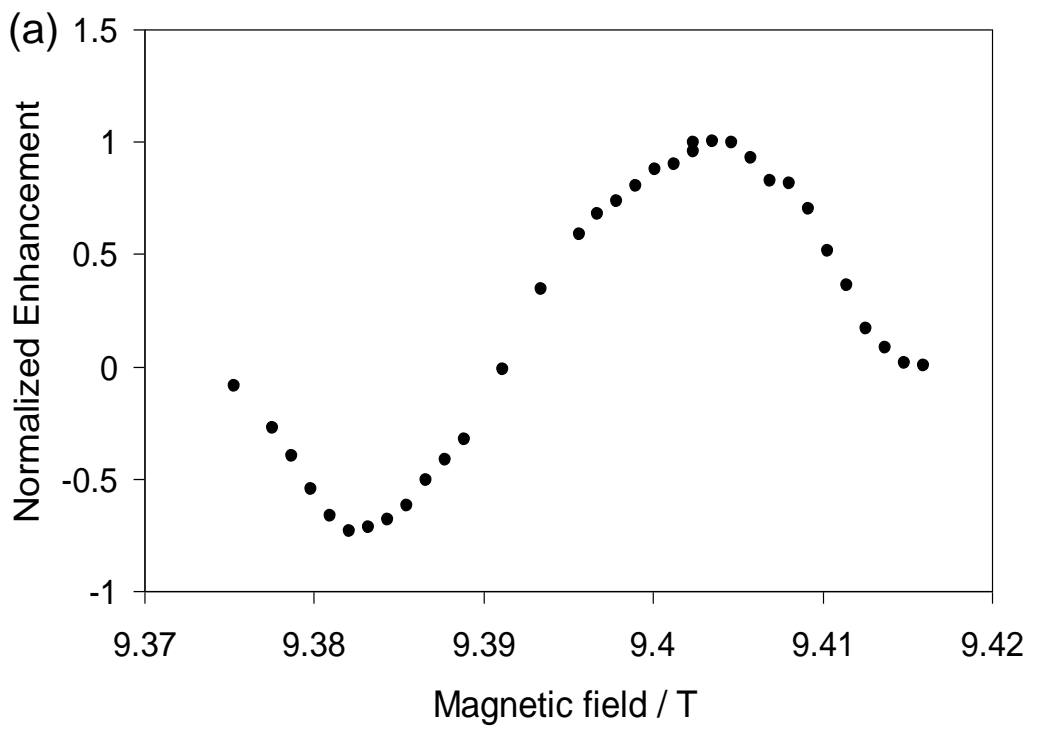

(b)

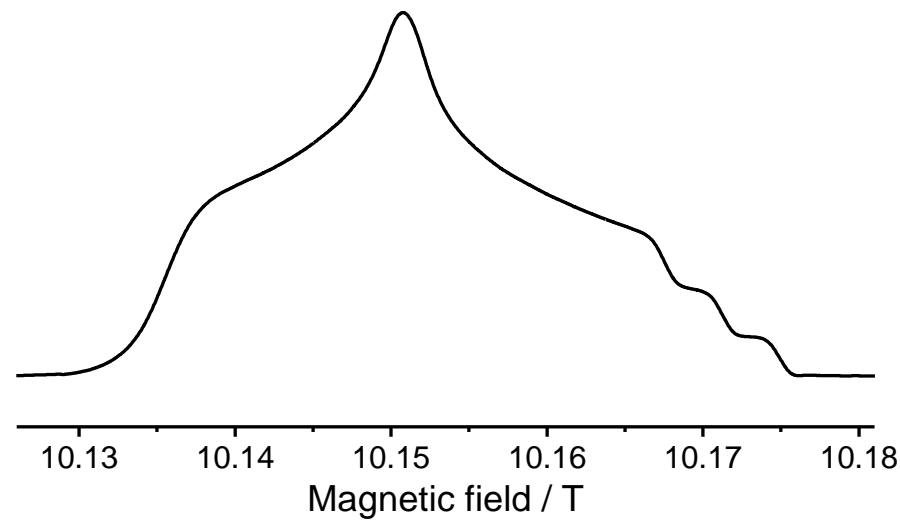

Figure 6. (a) DNP field profile on $2 \mathrm{M}{ }^{13} \mathrm{C}$-urea with $15 \mathrm{mM}$ TOTAPOL in $\mathrm{d}_{8}$-glycerol/ $\mathrm{D}_{2} \mathrm{O} / \mathrm{H}_{2} \mathrm{O}(6: 3: 1$ by volume) recorded at $105 \mathrm{~K}$ and MAS frequency of $8 \mathrm{kHz}$. (b) EPR absorption spectrum at $10 \mathrm{~T}$ and $101 \mathrm{~K}$ on $2 \mathrm{M}{ }^{13} \mathrm{C}$-urea with $20 \mathrm{mM}$ TOTAPOL in $\mathrm{d}_{6}-\mathrm{DMSO} / \mathrm{D}_{2} \mathrm{O} / \mathrm{H}_{2} \mathrm{O}$ (6:3:1 by volume).

Measurement of relaxation times of electron spins $\left(T_{1 \mathrm{e}} / T_{2 \mathrm{e}}\right)$ is essential to improve our understanding of the DNP mechanism. However, such measurements are not straightforward to collect at high magnetic field (9.4 $\mathrm{T}$ in this case). In addition, DNP experiments are typically performed using radical concentrations one to two orders of magnitude larger than those used in EPR studies, which can significantly complicate data analysis. Nevertheless, even in the absence of direct measurements of electron spin relaxation times, their variations can be indirectly probed by measuring nuclear relaxation time decays (as long as paramagnetic effects significantly contribute to these nuclear time decays). In fact, nuclear time decays at $105 \mathrm{~K}$ and $20 \mathrm{mM}$ TOTAPOL concentration are mainly dominated by the presence of radicals as seen in 
section 3.2 .

As seen in Fig. 5(a), all parameters except for $T_{2} *$ drop drastically above around $140 \mathrm{~K}$ in a d $6^{-}$ $\mathrm{DMSO} / \mathrm{D}_{2} \mathrm{O} / \mathrm{H}_{2} \mathrm{O}$ (6:3:1 by volume) solution, which corresponds to the glass transition temperature found in the literature [67]. This suggests that another relaxation mechanism appears above that temperature yielding significantly shorter $T_{1 \mathrm{e}} . T_{1 \mathrm{n}}$ was also measured at various temperatures on the same sample as used for Fig. 5(a) in absence of radical doping (Fig. 7). The same tendency as in Fig. 5(a) is observed (with longer $T_{1 \mathrm{n}}$ relaxation times). These results presumably arise from molecular motion caused by softening of the glass. Impact of such glass softening is discussed in detail below both in terms of DNP enhancements (owing to shortening of $T_{1 \mathrm{e}}$ ) and possible microwave absorption.

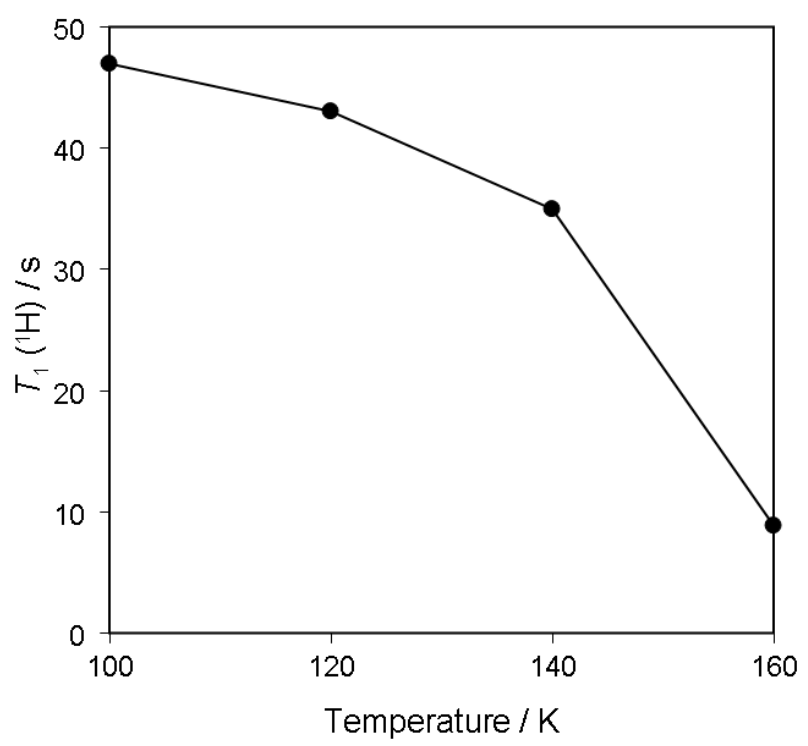

Figure 7. Temperature dependence of proton $T_{1}$ relaxation time constant in the absence of polarizing agents. The composition of the glassy solution is the same as for Fig. 5.

As seen in Fig. 5(a), EDNP drops drastically as the sample temperature increases. This may be related to relaxation times of electron spins. In fact, Sato et al. reported the temperature dependence of electron spin-lattice relaxation time $\left(T_{1 \mathrm{e}}\right)$ of nitroxyl radicals in glassy solutions at X-band [74]. $T_{1 \mathrm{e}}$ shortens rapidly above glass-softening temperature since the motion-dependent process (relaxation due to spin rotation and modulation of $g$ and $A$ anisotropies) becomes dominant in the relaxation mechanism.

At $\mathrm{X}$-band and $100 \mathrm{~K}$ on glycerol/ $\mathrm{H}_{2} \mathrm{O}$ mixture, the dominant relaxation mechanism of electron 
spins is Raman process $\left(T_{1 \mathrm{e}} \propto T^{-2}\right)$ and modulation of $g$-anisotropy does not contribute to it. However, the effect of modulation of $g$-anisotropy possesses $B_{0}{ }^{-2}$ dependence on $T_{1 \mathrm{e}}$ according to the above literature [74], thus such modulation can be a dominant mechanism at $9.4 \mathrm{~T}$ or especially above even in the case of slow motion. Therefore, rigidity of glass, which depends on the temperature and the composition of the DNP solution, has to be considered for high-field DNP experiments to obtain a long $T_{1 \mathrm{e}}$ at high fields.

To further investigate the temperature dependence of $\varepsilon$ DNP, EPR spectra of the same sample as in Fig. 5(a), $20 \mathrm{mM}$ TOTAPOL with $2 \mathrm{M}{ }^{13} \mathrm{C}$-urea in $\mathrm{d}_{6}-\mathrm{DMSO} / \mathrm{D}_{2} \mathrm{O} / \mathrm{H}_{2} \mathrm{O}(6: 3: 1$ by volume), was measured at $10 \mathrm{~T}$ in the temperature range between 100 and $175 \mathrm{~K}$ (Fig. 8a). Note that microwave absorption by TOTAPOL radical is detected and monitored without a cavity and that the absorption occurs over several wavelengths on this EPR setup (Fig. 8b). It is very important to understand that this is somewhat similar to the setup used in MAS-DNP experiments. As the temperature increases, the signal intensity of EPR spectra decreases much more rapidly than the Curie Law. This is an interesting phenomenon that requires further investigations.

Firstly the same experiments were repeated at X-band using a cavity where the sample was placed (in order to minimize E-field). In this case, the EPR signal intensities exactly followed Curie's law (data not shown). At this point, we clearly wonder whether the glass softening phenomenon (discussed above) can explain alone the drastic decay in EPR signals intensity observed at high magnetic field in absence of cavity. Since the frozen solutions are slightly "softened" when approaching the glass transition they might lead to increased non-resonant microwave absorption and thus to a decay in CW EPR intensity.

To prove this hypothesis, we first tried to indirectly detect the microwave absorption through the precise measurement of the sample-temperature increase arising when the microwave irradiation is applied. This temperature increase is expected to become larger when the microwave absorption is higher, e.g. at higher absolute temperature. The experiments performed on the urea sample were, however, not conclusive, as the temperature difference of the sample with and without microwave irradiation did not show any temperature dependence in the $100 \mathrm{~K}-160 \mathrm{~K}$ range. Due to this protocol being not suitable to detect variations in microwave absorption by the DNP matrix, under our experimental conditions, it was therefore 
further investigated using high-field EPR at $10 \mathrm{~T}(285 \mathrm{GHz})$. The DNP matrix (same as above but without TOTAPOL) was placed on top of a $\mathrm{MnO} / \mathrm{MgO}(0.01 \% \mathrm{MnO})$ mixture and microwaves were irradiated from the top (Fig. 8c). Figure 8(d) shows the experimentally obtained EPR signal intensities of MnO (filled circles). We then checked for a few temperature points that in absence of DNP matrix the MnO signals were very close to a Curie law (open circles and solid line). The discrepancy between both tendencies clearly indicates a variation in microwave absorption by the DNP matrix placed on the top on the $\mathrm{MnO} / \mathrm{MgO}$ sample. This microwave absorption by glassy matrices at higher field has not been investigated due to the unavailability of an EPR setup at such high field. It is important to note that this phenomenon could become more serious at higher field.

Finally, EDNP and the calibrated EPR signal intensities of TOTAPOL (the contribution from Curie's law is removed from Fig. 8(a) and therefore the main contribution is microwave absorption of the DNP matrix) are compared at various temperatures (Fig. 8e). They show the similar tendency as a function of temperature, which suggests that DNP efficiency is largely affected by microwave absorption of the DNP matrix. Further drop on $\varepsilon_{\mathrm{DNP}}$ can be explained by a shortening of relaxation times of electron spins as discussed earlier.

Both microwave absorption by DNP matrices and shortening of relaxation times are affected by the quality of the glass formed by DNP matrices. Glass rigidity is a very important factor to be considered to obtain large EDNP. One way to improve it is obviously lowering sample temperatures, which then lengthens the relaxation times of electron spins and avoids microwave absorption by DNP matrices. Another possible way (which does not require new instrumentation developments) is matrix-free DNP (MF-DNP) $[40,75,76]$ where the motion-dependent process should not be a dominant mechanism for relaxation due to the absence of solvents. Furthermore, microwave absorption by DNP matrices is avoided in this case. MFDNP has not yet been extensively studied in these aspects but it might be a favorable choice for sample preparation at a higher magnetic field. 

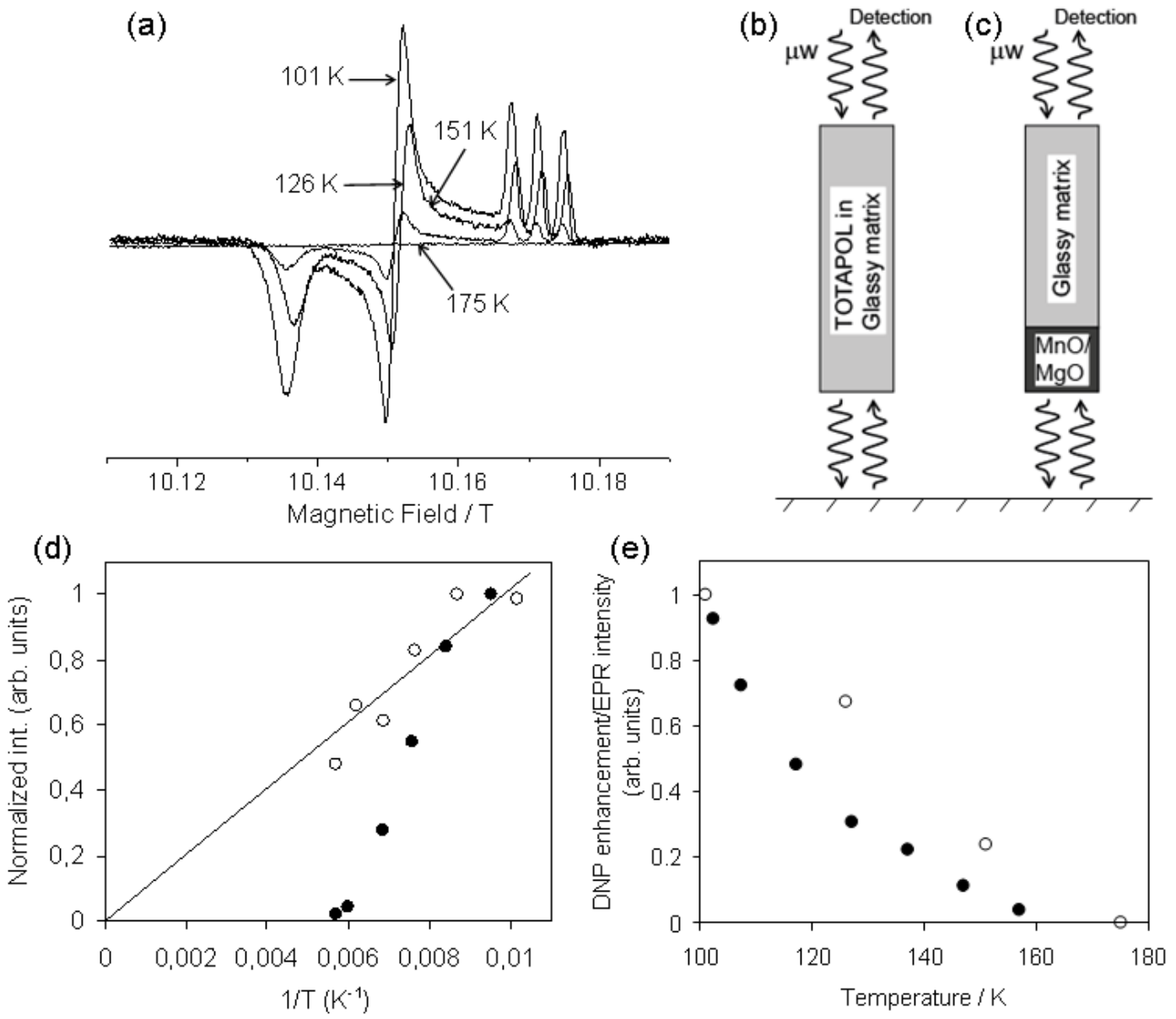

Figure 8. (a) $285 \mathrm{GHz} \mathrm{CW}$ EPR spectra on $20 \mathrm{mM}$ TOTAPOL with $2 \mathrm{M}{ }^{13} \mathrm{C}$-urea in $\mathrm{d}_{6}-\mathrm{DMSO} / \mathrm{D}_{2} \mathrm{O} / \mathrm{H}_{2} \mathrm{O}$ $(6: 3: 1$ by volume) at various temperatures. $(b, c)$ Schematic pictures of the sample tubes. Microwaves are irradiated into the samples and detected without a cavity. (d) Temperature dependence of $285 \mathrm{GHz}$ EPR signal intensities of the reference sample of $\mathrm{MnO} / \mathrm{MgO}$ only (open circles), and of $\mathrm{MnO} / \mathrm{MgO}$ placed at the bottom of the glassy matrix as describe in c) (filled circles). Best fit of the reference-sample measurements according to Curie's law is indicated by a solid line. (e) Temperature dependence of the normalized DNP enhancement of the ${ }^{13} \mathrm{C}$ Urea signal after CP (filled circles), and calibrated $285 \mathrm{GHz}$ EPR signal intensities of TOTAPOL in the glassy matrix (open circles).

\section{Conclusions}

We have demonstrated TOTAPOL concentration and sample temperature dependence of MAS-DNP experiments at 9.4 T. $T_{1}, T_{1}$ and $T_{2}$ ' are severely affected by paramagnetic effects and glass conditions, whereas $T_{2}^{*}$ is insensitive since it is mostly dominated by chemical shift distribution in a frozen solution. 
All parameters that affect an effective DNP enhancement in multidimensional SSNMR experiments were taken into account. By choosing an adequate concentration of polarizing agents and optimizing sample conditions, a DNP-enhanced ${ }^{13} \mathrm{C}-{ }^{13} \mathrm{C} 2 \mathrm{D}$ refocused INADEQUATE spectrum of natural-abundance semicrystalline cellulose suspended in a typical DNP matrix doped with TOTAPOL was obtained in a reasonable experimental time.

Furthermore, the temperature dependence of DNP experiments was rationalized with high-field EPR experiments on the same sample at the same magnetic field. Shortening of electron spin relaxation times at high field and microwave absorption by DNP matrices depend on the glass condition, which then affect the DNP enhancement and nuclear spin relaxation times. At higher field, these contributions might

become larger and bring additional reduction of $\varepsilon_{\mathrm{DNP}}$ along with the $B_{0}{ }^{-1}$ dependence of $\varepsilon_{\mathrm{DNP}}$ and the $B_{0}{ }^{3}$ dependence of the polarization transfer time constant.

\section{Acknowledgments}

This work was partially supported by the French National Research Agency through the "programme blanc" (ANR-12-BS08-0016-01), the Labex ARCANE (ANR-11-LABX-0003-01) and funding from the RTB. 


\section{References}

[1] A.W. Overhauser, Polarization of nuclei in metals, Phys. Rev. 92 (1953) 411-415.

[2] T.R. Carver, C.P. Slichter, Polarization of nuclear spins in metals, Phys. Rev. 92 (1953) 212-213.

[3] T.P. Carver, C.P. Slichter, Experimental verification of the Overhauser nuclear polarization effect, Phys. Rev. 102 (1956) 975-980.

[4] A. Abragam, M. Goldman, Principles of dynamic nuclear-polarization, Rep. Prog. Phys. 41 (1978) 395467.

[5] R.A. Wind, M.J. Duijvestijn, C. van der Lugt, A. Manenschijn, J. Vriend, Applications of dynamic nuclear polarization in C-13 NMR in solids, Prog. Nucl. Magn. Reson. Spectrosc. 17 (1985) 33-67.

[6] C.D. Joye, R.G. Griffin, M.K. Hornstein, K.N. Hu, K.E. Kreischer, M. Rosay, M.A. Shapiro, J.R. Sirigiri, R.J. Temkin, P.P. Woskov, Operational characteristics of a 14-W 140-GHz gyrotron for dynamic nuclear polarization, IEEE Trans. Plasma Sci. 34 (2006) 518-523.

[7] V.S. Bajaj, M.K. Hornstein, K.E. Kreischer, J.R. Sirigiri, P.P. Woskov, M.L. Mak-Jurkauskas, J. Herzfeld, R.J. Temkin, R.G. Griffin, $250 \mathrm{GHz} \mathrm{CW}$ gyrotron oscillator for dynamic nuclear polarization in biological solid state NMR, J. Magn. Reson. 189 (2007) 251-279.

[8] T. Idehara, I. Ogawa, L. Agusu, T. Kanemaki, S. Mitsudo, T. Saito, T. Fujiwara, H. Takahashi, Development of 394.6 GHz CW gyrotron (Gyrotron FUCWII) for DNP/proton-NMR at $600 \mathrm{MHz}$, Int. J. Infrared Millimeter Waves 28 (2007) 433-442.

[9] A.C. Torrezan, S.T. Han, I. Mastovsky, M.A. Shapiro, J.R. Sirigiri, R.J. Temkin, A.B. Barnes, R.G. Griffin, Continuous-wave operation of a frequency-tunable 460-GHz second-harmonic gyrotron for enhanced nuclear magnetic resonance, IEEE Trans. Plasma Sci. 38 (2010) 1150-1159.

[10] Y. Matsuki, K. Ueda, T. Idehara, R. Ikeda, K. Kosuga, I. Ogawa, S. Nakamura, M. Toda, T. Anai, T. Fujiwara, Application of continuously frequency-tunable $0.4 \mathrm{THz}$ gyrotron to dynamic nuclear polarization for 600 MHz solid-state NMR, J. Infred Millim. Teraherz. 33 (2012) 745-755.

[11] K.J. Pike, T.F. Kemp, H. Takahashi, R. Day, A.P. Howes, E.V. Kryukov, J.F. MacDonald, A.E.C. Collis, D.R. Bolton, R.J. Wylde, M. Orwick, K. Kosuga, A.J. Clark, T. Idehara, A. Watts, G.M. Smith, M.E. Newton, 
R. Dupree, M.E. Smith, A spectrometer designed for 6.7 and 14.1 T DNP-enhanced solid-state MAS NMR using quasi-optical microwave transmission, J. Magn. Reson. 215 (2012) 1-9.

[12] P.P. Woskov, V.S. Bajaj, M.K. Hornstein, R.J. Temkin, R.G. Griffin, Corrugated waveguide and directional coupler for CW 250-GHz gyrotron DNP experiments, IEEE Trans. Microw. Theory Tech. 53 (2005) 1863-1869.

[13] K.R. Thurber, W.M. Yau, R. Tycko, Low-temperature dynamic nuclear polarization at 9.4 T with a 30 mW microwave source, J. Magn. Reson. 204 (2010) 303-313.

[14] A.A. Bogdashov, V.I. Belousov, A.V. Chirkov, G.G. Denisov, V.V. Korchagin, S.Y. Kornishin, E.M. Tai, Transmission line for 258 GHz gyrotron DNP spectrometry, J. Infred Millim. Teraherz. 32 (2011) 823837.

[15] A.B. Barnes, M.L. Mak-Jurkauskas, Y. Matsuki, V.S. Bajaj, P.C.A. van der Wel, R. DeRocher, J. Bryant, J.R. Sirigiri, R.J. Temkin, J. Lugtenburg, J. Herzfeld, R.G. Griffin, Cryogenic sample exchange NMR probe for magic angle spinning dynamic nuclear polarization, J. Magn. Reson. 198 (2009) 261-270.

[16] Y. Matsuki, K. Ueda, T. Idehara, R. Ikeda, I. Ogawa, S. Nakamura, M. Toda, T. Anai, T. Fujiwara, Helium-cooling and -spinning dynamic nuclear polarization for sensitivity-enhanced solid-state NMR at 14 T and 30 K, J. Magn. Reson. 225 (2012) 1-9.

[17] K.N. Hu, H.H. Yu, T.M. Swager, R.G. Griffin, Dynamic nuclear polarization with biradicals, J. Am. Chem. Soc. 126 (2004) 10844-10845.

[18] C. Ysacco, E. Rizzato, M.A. Virolleaud, H. Karoui, A. Rockenbauer, F. Le Moigne, D. Siri, O. Ouari, R.G. Griffin, P. Tordo, Properties of dinitroxides for use in dynamic nuclear polarization (DNP), Phys. Chem. Chem. Phys. 12 (2010) 5841-5845.

[19] K.N. Hu, Polarizing agents and mechanisms for high-field dynamic nuclear polarization of frozen dielectric solids, Solid State Nucl. Magn. Reson. 40 (2011) 31-41.

[20] C. Song, K.N. Hu, C.G. Joo, T.M. Swager, R.G. Griffin, TOTAPOL: a biradical polarizing agent for dynamic nuclear polarization experiments in aqueous media, J. Am. Chem. Soc. 128 (2006) 11385-11390. [21] Y. Matsuki, T. Maly, O. Ouari, H. Karoui, F. Le Moigne, E. Rizzato, S. Lyubenova, J. Herzfeld, T. 
Prisner, P. Tordo, R.G. Griffin, Dynamic nuclear polarization with a rigid biradical, Angew. Chem., Int. Ed. 48 (2009) 4996-5000.

[22] A.B. Barnes, G. De Paëpe, P.C.A. van der Wel, K. Hu, C. Joo, V.S. Bajaj, M.L. Mak-Jurkauskas, J.R. Sirigiri, J. Herzfeld, R.J. Temkin, R.G. Griffin, High-field dynamic nuclear polarization for solid and solution biological NMR, Appl. Magn. Reson. 34 (2008) 237-263.

[23] T. Maly, G.T. Debelouchina, V.S. Bajaj, K.N. Hu, C.G. Joo, M.L. Mak-Jurkauskas, J.R. Sirigiri, P.C. van der Wel, J. Herzfeld, R.J. Temkin, R.G. Griffin, Dynamic nuclear polarization at high magnetic fields, J. Chem. Phys. 128 (2008) 052211.

[24] K.N. Hu, C. Song, H.H. Yu, T.M. Swager, R.G. Griffin, High-frequency dynamic nuclear polarization using biradicals: a multifrequency EPR lineshape analysis, J. Chem. Phys. 128 (2008) 052302.

[25] M. Rosay, L. Tometich, S. Pawsey, R. Bader, R. Schauwecker, M. Blank, P.M. Borchard, S.R. Cauffman, K.L. Felch, R.T. Weber, R.J. Temkin, R.G. Griffin, W.E. Maas, Solid-state dynamic nuclear polarization at $263 \mathrm{GHz}$ : spectrometer design and experimental results, Phys. Chem. Chem. Phys. 12 (2010) $5850-5860$.

[26] E.A. Nanni, A.B. Barnes, R.G. Griffin, R.J. Temkin, THz dynamic nuclear polarization NMR, IEEE Trans. Teraherz. Tech. 1 (2011) 145-163.

[27] L.R. Becerra, G.J. Gerfen, R.J. Temkin, D.J. Singel, R.G. Griffin, Dynamic nuclear-polarization with a cyclotron-resonance maser at 5-T, Phys. Rev. Lett. 71 (1993) 3561-3564.

[28] L.R. Becerra, G.J. Gerfen, B.F. Bellew, J.A. Bryant, D.A. Hall, S.J. Inati, R.T. Weber, S. Un, T.F. Prisner, A.E. McDermott, K.W. Fishbein, K.E. Kreischer, R.J. Temkin, D.J. Singel, R.G. Griffin, A spectrometer for dynamic nuclear-polarization and electron-paramagnetic-resonance at high-frequencies, J. Magn. Reson. A 117 (1995) 28-40.

[29] G.J. Gerfen, L.R. Becerra, D.A. Hall, R.G. Griffin, R.J. Temkin, D.J. Singel, High-frequency (140 Ghz) dynamic nuclear-polarization - polarization transfer to a solute in frozen aqueous-solution, J. Chem. Phys. 102 (1995) 9494-9497.

[30] D.A. Hall, D.C. Maus, G.J. Gerfen, S.J. Inati, L.R. Becerra, F.W. Dahlquist, R.G. Griffin, Polarization- 
enhanced NMR spectroscopy of biomolecules in frozen solution, Science 276 (1997) 930-932.

[31] V.S. Bajaj, C.T. Farrar, M.K. Hornstein, I. Mastovsky, J. Vieregg, J. Bryant, B. Elena, K.E. Kreischer, R.J. Temkin, R.G. Griffin, Dynamic nuclear polarization at 9T using a novel 250GHz gyrotron microwave source, J. Magn. Reson. 160 (2003) 85-90.

[32] Y. Matsuki, H. Takahashi, K. Ueda, T. Idehara, I. Ogawa, M. Toda, H. Akutsu, T. Fujiwara, Dynamic nuclear polarization experiments at 14.1 T for solid-state NMR, Phys. Chem. Chem. Phys. 12 (2010) 57995803.

[33] A.B. Barnes, E. Markhasin, E. Daviso, V.K. Michaelis, E.A. Nanni, S.K. Jawla, E.L. Mena, R. DeRocher, A. Thakkar, P.P. Woskov, J. Herzfeld, R.J. Temkin, R.G. Griffin, Dynamic nuclear polarization at $700 \mathrm{MHz} / 460 \mathrm{GHz}$, J. Magn. Reson. 224 (2012) 1-7.

[34] P. Mieville, V. Vitzthum, M.A. Caporini, S. Jannin, S. Gerber-Lemaire, G. Bodenhausen, A spinning thermometer to monitor microwave heating and glass transitions in dynamic nuclear polarization, Magn. Reson. Chem. 49 (2011) 689-692.

[35] S. Lange, A.H. Linden, U. Akbey, W.T. Franks, N.M. Loening, B.J. van Rossum, H. Oschkinat, The effect of biradical concentration on the performance of DNP-MAS-NMR, J. Magn. Reson. 216 (2012) 209212.

[36] A.H. Linden, S. Lange, W.T. Franks, U. Akbey, E. Specker, B.J. van Rossum, H. Oschkinat, Neurotoxin II bound to acetylcholine receptors in native membranes studied by dynamic nuclear polarization NMR, J. Am. Chem. Soc. 133 (2011) 19266-19269.

[37] L. Reggie, J.J. Lopez, I. Collinson, C. Glaubitz, M. Lorch, Dynamic nuclear polarization-enhanced solid-state NMR of a C-13-labeled signal peptide bound to lipid-reconstituted Sec translocon, J. Am. Chem. Soc. 133 (2011) 19084-19086.

[38] T. Jacso, W.T. Franks, H. Rose, U. Fink, J. Broecker, S. Keller, H. Oschkinat, B. Reif, Characterization of membrane proteins in isolated native cellular membranes by dynamic nuclear polarization solid-state NMR spectroscopy without purification and reconstitution, Angew. Chem., Int. Ed. 51 (2012) 432-435.

[39] V. Vitzthum, F. Borcard, S. Jannin, M. Morin, P. Mieville, M.A. Caporini, A. Sienkiewicz, S. Gerber- 
Lemaire, G. Bodenhausen, Fractional spin-labeling of polymers for enhancing NMR sensitivity by solventfree dynamic nuclear polarization, ChemPhysChem 12 (2011) 2929-2932.

[40] H. Takahashi, D. Lee, L. Dubois, M. Bardet, S. Hediger, G. De Paëpe, Rapid natural-abundance 2D (13) C-(13) C correlation spectroscopy using dynamic nuclear polarization enhanced solid-state NMR and matrix-free sample preparation, Angew. Chem., Int. Ed. 51 (2012) 11766-11769.

[41] A.J. Rossini, A. Zagdoun, M. Lelli, J. Canivet, S. Aguado, O. Ouari, P. Tordo, M. Rosay, W.E. Maas, C. Copéret, D. Farrusseng, L. Emsley, A. Lesage, Dynamic nuclear polarization enhanced solid-state NMR spectroscopy of functionalized metal-organic frameworks, Angew. Chem., Int. Ed. 51 (2012) 123-127.

[42] D. Lee, H. Takahashi, A.S.L. Thankamony, J.P. Dacquin, M. Bardet, O. Lafon, G. De Paëpe, Enhanced solid-state NMR correlation spectroscopy of quadrupolar nuclei using dynamic nuclear polarization, J. Am. Chem. Soc. 134 (2012) 18491-18494.

[43] H. Takahashi, I. Ayala, M. Bardet, G. De Paëpe, J.P. Simorre, S. Hediger, Solid-state NMR on bacterial cells: selective cell wall signal enhancement and resolution improvement using dynamic nuclear polarization, J. Am. Chem. Soc. 135 (2013) 5105-5110.

[44] T. Kobayashi, O. Lafon, A.S.L. Thankamony, I.I. Slowing, K. Kandel, D. Carnevale, V. Vitzthum, H. Vezin, J.P. Amoureux, G. Bodenhausen, M. Pruski, Analysis of sensitivity enhancement by dynamic nuclear polarization in solid-state NMR: a case study of functionalized mesoporous materials, Phys. Chem. Chem. Phys. 15 (2013) 5553-5562.

[45] M. Rosay, V. Weis, K.E. Kreischer, R.J. Temkin, R.G. Griffin, Two-dimensional C-13-C-13 correlation spectroscopy with magic angle spinning and dynamic nuclear polarization, J. Am. Chem. Soc. 124 (2002) 3214-3215.

[46] M. Rosay, J.C. Lansing, K.C. Haddad, W.W. Bachovchin, J. Herzfeld, R.J. Temkin, R.G. Griffin, Highfrequency dynamic nuclear polarization in MAS spectra of membrane and soluble proteins, J. Am. Chem. Soc. 125 (2003) 13626-13627.

[47] U. Akbey, W.T. Franks, A. Linden, S. Lange, R.G. Griffin, B.J. van Rossum, H. Oschkinat, Dynamic nuclear polarization of deuterated proteins, Angew. Chem., Int. Ed. 49 (2010) 7803-7806. 
[48] M. Rosay, A.C. Zeri, N.S. Astrof, S.J. Opella, J. Herzfeld, R.G. Griffin, Sensitivity-enhanced NMR of biological solids: Dynamic nuclear polarization of Y21M fd bacteriophage and purple membrane, J. Am. Chem. Soc. 123 (2001) 1010-1011.

[49] P.C.A. van der Wel, K.-N. Hu, J. Lewandoswki, R.G. Griffin, Dynamic nuclear polarization of amyloidogenic peptide nanocrystals: GNNQQNY, a core segment of the yeast prion protein Sup35p, J. Am. Chem. Soc. 128 (2006) 10840-10846.

[50] M.L. Mak-Jurkauskas, V.S. Bajaj, M.K. Hornstein, M. Belenky, R.G. Griffin, J. Herzfeld, Energy transformations early in the bacteriorhodopsin photocycle revealed by DNP-enhanced solid-state NMR, Proc. Natl. Acad. Sci. USA 105 (2008) 883-888.

[51] V.S. Bajaj, M.L. Mak-Jurkauskas, M. Belenky, J. Herzfeld, R.G. Griffin, Functional and shunt states of bacteriorhodopsin resolved by $250 \mathrm{GHz}$ dynamic nuclear polarization-enhanced solid-state NMR, Proc. Natl. Acad. Sci. USA 106 (2009) 9244-9249.

[52] V.S. Bajaj, M.L. Mak-Jurkauskas, M. Belenky, J. Herzfeld, R.G. Griffin, DNP enhanced frequencyselective TEDOR experiments in bacteriorhodopsin, J. Magn. Reson. 202 (2010) 9-13.

[53] G.T. Debelouchina, M.J. Bayro, P.C. van der Wel, M.A. Caporini, A.B. Barnes, M. Rosay, W.E. Maas, R.G. Griffin, Dynamic nuclear polarization-enhanced solid-state NMR spectroscopy of GNNQQNY nanocrystals and amyloid fibrils, Phys. Chem. Chem. Phys. 12 (2010) 5911-5919.

[54] A.B. Barnes, B. Corzilius, M.L. Mak-Jurkauskas, L.B. Andreas, V.S. Bajaj, Y. Matsuki, M.L. Belenky, J. Lugtenburg, J.R. Sirigiri, R.J. Temkin, J. Herzfeld, R.G. Griffin, Resolution and polarization distribution in cryogenic DNP/MAS experiments, Phys. Chem. Chem. Phys. 12 (2010) 5861-5867.

[55] M.J. Bayro, G.T. Debelouchina, M.T. Eddy, N.R. Birkett, C.E. MacPhee, M. Rosay, W.E. Maas, C.M. Dobson, R.G. Griffin, Intermolecular structure determination of amyloid fibrils with magic-angle spinning and dynamic nuclear polarization NMR, J. Am. Chem. Soc. 133 (2011) 13967-13974.

[56] I.V. Sergeyev, L.A. Day, A. Goldbourt, A.E. McDermott, Chemical shifts for the unusual DNA structure in Pf1 bacteriophage from dynamic-nuclear-polarization-enhanced solid-state NMR spectroscopy, J. Am. Chem. Soc. 133 (2011) 20208-20217. 
[57] M. Renault, S. Pawsey, M.P. Bos, E.J. Koers, D. Nand, R. Tommassen-van Boxtel, M. Rosay, J. Tommassen, W.E. Maas, M. Baldus, Solid-state NMR spectroscopy on cellular preparations enhanced by dynamic nuclear polarization, Angew. Chem., Int. Ed. 51 (2012) 2998-3001.

[58] A. Lesage, M. Bardet, L. Emsley, Through-bond carbon-carbon connectivities in disordered solids by NMR, J. Am. Chem. Soc. 121 (1999) 10987-10993.

[59] D. Lee, J. Struppe, D.W. Elliott, L.J. Mueller, J.J. Titman, Sensitive absorptive refocused scalar correlation NMR spectroscopy in solids, Phys. Chem. Chem. Phys. 11 (2009) 3547-3553.

[60] G. De Paëpe, N. Giraud, A. Lesage, P. Hodgkinson, A. Bockmann, L. Emsley, Transverse dephasing optimized solid-state NMR spectroscopy, J. Am. Chem. Soc. 125 (2003) 13938-13939.

[61] A. Potapov, K.R. Thurber, W.M. Yau, R. Tycko, Dynamic nuclear polarization-enhanced ${ }^{1} \mathrm{H}-{ }^{13} \mathrm{C}$ double resonance NMR in static samples below 20K, J. Magn. Reson. 221 (2012) 32-40.

[62] A.J. Rossini, A. Zagdoun, M. Lelli, D. Gajan, F. Rascon, M. Rosay, W.E. Maas, C. Copéret, A. Lesage, L. Emsley, One hundred fold overall sensitivity enhancements for Silicon-29 NMR spectroscopy of surfaces by dynamic nuclear polarization with CPMG acquisition, Chem. Sci. 3 (2012) 108-115.

[63] B.M. Fung, A.K. Khitrin, K. Ermolaev, An improved broadband decoupling sequence for liquid crystals and solids, J. Magn. Reson. 142 (2000) 97-101.

[64] K.R. Thurber, R. Tycko, Measurement of sample temperatures under magic-angle spinning from the chemical shift and spin-lattice relaxation rate of Br-79 in KBr powder, J. Magn. Reson. 196 (2009) 84-87. [65] A.L. Barra, A.K. Hassan, A. Janoschka, C.L. Schmidt, V. Schunemann, Broad-band quasi-optical HFEPR spectroscopy: Application to the study of the ferrous iron center from a rubredoxin mutant, Appl. Magn. Reson. 30 (2006) 385-397.

[66] A.H. Linden, W.T. Franks, U. Akbey, S. Lange, B.J. van Rossum, H. Oschkinat, Cryogenic temperature effects and resolution upon slow cooling of protein preparations in solid state NMR, J. Biomol. NMR 51 (2011) 283-292.

[67] J. Mala, I. Slama, Temperature of glass transitions and the glass-forming region in the system lithium nitrate - dimethyl sulfoxide - water, Chem. Zvesti 38 (1984) 395-403. 
[68] A.V. Kessenikh, A.A. Manenkov, G.I. Pyatnitskii, On explanation of experimtnat data on dynamic polarization of protons in irradiated polyethylenes, Sov. Phys. Solid State 6 (1964) 641-643.

[69] C.F. Hwang, D.A. Hill, Phenomenological model for the new effect in dynamic polarization, Phys. Rev. Lett. 19 (1967) 1011-1013.

[70] D.S. Wollan, Dynamic nuclear-polarization with an inhomogeneously broadened ESR line. 1. Theory, Phys. Rev. B 13 (1976) 3671-3685.

[71] K.N. Hu, G.T. Debelouchina, A.A. Smith, R.G. Griffin, Quantum mechanical theory of dynamic nuclear polarization in solid dielectrics, J. Chem. Phys. 134 (2011) 125105.

[72] K.R. Thurber, R. Tycko, Theory for cross effect dynamic nuclear polarization under magic-angle spinning in solid state nuclear magnetic resonance: The importance of level crossings, J. Chem. Phys. 137 (2012) 084508.

[73] F. Mentink-Vigier, U. Akbey, Y. Hovav, S. Vega, H. Oschkinat, A. Feintuch, Fast passage dynamic nuclear polarization on rotating solids, J. Magn. Reson. 224 (2012) 13-21.

[74] H. Sato, S.E. Bottle, J.P. Blinco, A.S. Micallef, G.R. Eaton, S.S. Eaton, Electron spin-lattice relaxation of nitroxyl radicals in temperature ranges that span glassy solutions to low-viscosity liquids, J. Mag. Reson. $191(2008) 66-77$.

[75] H. Takahashi, B. Viverge, D. Lee, P. Rannou, G. De Paepe, Towards structure determination of selfassembled peptides using dynamic nuclear polarization enhanced solid-state NMR spectroscopy, Angew. Chem., Int. Ed. 52 (2013) 6979-6982.

[76] H. Takahashi, S. Hediger, G. De Paepe, Matrix-free dynamic nuclear polarization enables solid-state NMR C-13-C-13 correlation spectroscopy of proteins at natural isotopic abundance, Chem. Comm. 49 (2013) 9479-9481. 